\title{
TRABALHO E PANDEMIA SOB O ENLACE DA FRATERNIDADE
}

Lucilaine Ignacio da Silva ${ }^{1}$

DOI: https://doi.org/10.47306/978-65-88213-03-2.246-258

Sumário: 1 Introdução; 2 O Paradoxo do Trabalho; 3 Pandemia e Trabalho - a estranheza do ócio; $4 \mathrm{O}$ enlace da Fraternidade; 5 Considerações finais; Referências.

\section{Introdução}

No dia 11 de março de 2020, a Organização Mundial da Saúde (OMS), através de seu diretor geral, Tedros Adhanom, declarou a mudança de classificação da doença causada pelo novo coronavírus (Sars-Cov-2), a Covid-19 como uma pandemia, devido a sua disseminação geográfica extremamente rápida.

A doença relatada pela primeira vez em Wuhan, China, em 31 de dezembro de 2019, vem acarretando sérios impactos econômicos e sociais que afetam sobremaneira o mundo do trabalho e consequentemente a subsistência e o bem-estar de milhões de pessoas.

Sob tal abordagem, consolidar o entendimento de que a temática laboral necessita medidas urgentes de prevenção e reflexão diante do cenário de grande instabilidade, justifica a investigação do presente artigo. Para tanto, o problema que se impõe gira em questionar: como é possível amenizar as questões transversais que assolam o trabalhador no período da pandemia. A hipótese articulada, confirma a Fraternidade como princípio jurídico que restabelece a identidade do trabalhador, pois ela considera as dimensões culturais, históricas e sociais, fundamentais para desempenhar um papel de transformação social.

Diante de tal justificativa, busca-se por objetivo geral demonstrar a fragilidade do trabalhador diante das vicissitudes ocasionadas pela pandemia da COVID-19, que será sistematizado a partir dos seguintes objetivos específicos: identificar o paradoxo do trabalho, evidenciar a estranheza causada ao ócio em tempos pandêmicos, e indicar a Fraternidade como instrumento de transformação social. Como marco teórico, destacam-se as reflexões de Antônio Maria Baggio, Chiara Lubich e Guy Standing.

\footnotetext{
${ }^{1}$ Doutora em Direito (UFSC). Mestre em Ciência Jurídica (UNIVALI); Especialista em Direito e Processo do Trabalho (AMATRA 12); Especialista em Direito para Organizações Públicas e Privadas (UNIVALI). Pesquisadora no grupo de pesquisa Núcleo de Pesquisa Direito e Fraternidade, da Universidade Federal de Santa Catarina (UFSC). Docente na Universidade do Vale do Itajaí (UNIVALI). E-mail: lucilaine@gmail.com
} 
No que concerne à metodologia, quanto à natureza, trata-se de pesquisa pura, pois descreve os efeitos do precariado advindos do processo da globalização no que tange às questões relacionadas ao trabalho com base em doutrina. Quanto à abordagem do problema, trata-se de estudo qualitativo. Quanto aos fins, é pesquisa descritiva, pois detalha a sujeição da relação de trabalho e as condições do trabalhador sob os efeitos degradantes aflorados durante a pandemia da COVID-19. O método de abordagem é o indutivo. Quanto ao método de interpretação é precipuamente sociológico. Quanto aos procedimentos técnicos são doutrinário e documental. Os resultados são apresentados em forma textual.

\section{O Paradoxo do trabalho}

A história do trabalho sempre esteve relacionada à abordagens históricas, conferindo a abertura de espaço para a reflexão ampla da classe trabalhadora, do movimento operário e do capitalismo. O trabalho, ao longo da história, sempre ocupou lugar em volta do qual as pessoas organizaram suas vidas, seja esse relacionado a um fato degradante ou enobrecedor (FERRARI, 2002, p. 22).

Da análise dos variados significados da expressão trabalhar, Battaglia (1958, pp. 1819) propicia o entendimento de que o conceito ou os conceitos atribuídos à essa expressão é que dão sentido ao termo, ou seja, para o baixo latim (tripaliare) e o verbo francês (travailler), o termo significa tortura, enquanto na expressão italiana (bisogna), no alemão (arbeit) e no inglês (labour e work), significa tarefa ou necessidade de algo a ser executado.

No sentido de que trabalho significa a execução de algo necessário, Arendt (2007, pp. 107-110), relaciona a expressão trabalho com a palavra grega poiesis, significando criar, fazer, fabricar algo por técnica ou arte, o que corrobora com o artificialismo da existência humana.

Vê-se portanto, que o trabalho reivindica um direito muito maior, um direito anterior e além de todas as formas tipicamente capitalistas ${ }^{2}$ de trabalhar. Para Zangrando (2008, p. 66) "[...] vê-se que o trabalho transcende a própria pessoa, servindo como desenvolvimento da vida comunitária". Nesse sentido, o trabalho é extensão da personalidade humana, que tanto pode ser avaliado como encargo, como algo degradante, desumano, como também pode ser

\footnotetext{
2 “[...] o capitalismo não é a mera busca de lucro. O capitalismo é um modo de produção, no qual se requer a transformação de tudo em mercadoria, incluindo o trabalho, para fins de favorecer o mercado de trocas, permitindo uma organização estrutural para favorecer a reprodução do capital a partir da exploração do trabalho, pressupondo, para tanto, a divisão da sociedade em duas classes mais evidentemente identificadas: a dos capitalistas, que detém o dinheiro, a propriedade e os meios de produção, e a dos trabalhadores expropriados e que não têm outra alternativa de sobrevivência a não ser a da venda da força de trabalho, segundo as leis naturais do livre jogo da oferta e da procura" (SOUTO MAIOR, 2011, p. 130).
} 
concebido como libertação, fonte de realização pessoal e de reconhecimento para si e para outrem.

Sob a vertente do trabalho como extensão da personalidade humana, é possível compreender que o direito ao trabalho constitui-se na existência de relacionalidade entre aquele que trabalha com a atividade (trabalho) que se elabora, é por certo, "[...] mediação essencial para a realização das necessidades humanas e para a construção da identidade, [...] construção de vínculos de solidariedade, e aprendizado ético e político. " (WANDELLI, 2016, p. 1027).

A compreensão do significado do trabalho, dependerá necessariamente do contexto histórico que está inserido. Assim, se a história do trabalho estiver relacionada à história da sobrevivência, ele será meio de subsistência; se sua história estiver atrelada à conquista, ele pode estar relacionado à pobreza e à riqueza, assim como, se sua história é sobre fazer um mundo melhor, ele pode ser compreendido como meio de salvação.

Danièle Linhart (2007, p. 42) ensina que o trabalho possui uma ambivalência que pode ser caracterizada sob duas vertentes, ou seja, a primeira delas é que não se pode viver sem trabalho, pois é ele quem dá sentido e valor ao tempo livre e à vida; e a segunda é que o trabalho estraga a vida, ou seja, impede de viver e de aproveitar a vida, pois este utiliza o tempo que poderia ser dedicado a viver. Vive-se, portanto, o paradoxo do sofrimento e da necessidade.

$\mathrm{O}$ trabalho acontece sempre em três mundos. O mundo objetivo, físico, que tem como critério a validade da ação e sua eficácia. O mundo social, das relações sociais, para o bom desempenho de uma produção, e gerenciar ao mesmo tempo as relações entre as pessoas, estabelecendo critérios do que venha a ser justo ou injusto, bem ou mal. E, por último, o terceiro mundo, o subjetivo, pois todo trabalho é vivido afetivamente por quem o faz. O trabalho nunca é neutro com relação à subjetividade. Ele constrói a identidade e a saúde ou destrói a identidade e cria a doença. No mundo subjetivo, o critério da ação é a autenticidade (DEJOURS, 1999, p. 82 e 83$)$.

O trabalho expressa o sentido da atividade humana e não pode ser considerado somente como fonte de produção e de resultados (GAULEJAC, 2007, p. 289). O sujeito humano aspira o desejo de se construir e de se realizar com dignidade, e a maneira pela qual isso toma forma, é pelo trabalho. Além disso, conforme já se tem conhecimento, o artigo $1^{\circ}$ da Declaração Universal dos Direitos do Homem, proclama que "Todos os seres humanos nascem livres e iguais em dignidade e direitos. São dotados de razão e consciência e devem agir em relação uns aos outros com espírito de fraternidade. " (DUDH, 1948, art. $1^{\circ}$ ).

Importa recordar que, na segunda metade do século XVIII a mecanização do setor têxtil eclodiu no aumento da produção e na diminuição da necessidade de mão de obra, de modo 
que as relações de produção foram alteradas. Foi o alvorecer da Revolução Industrial que perdurou até o século XIX.

[...] o mercado de trabalho foi o último dos mercados a ser organizado sob o novo sistema industrial, e esse passo final só foi tomado quando a economia de mercado foi posta em marcha e a ausência de um mercado de trabalho provou ser um mal ainda maior para o próprio povo comum do que as calamidades que acompanhariam a sua introdução. (POLANYI, 2000, p. 99).

O principal local de trabalho passa a ser nas cidades, especialmente dentro das fábricas, sendo a máquina a vapor utilizada por vários segmentos industriais e, dentre muitos eventos ocorridos na época, Azevedo Neto (2015, p. 37)

\footnotetext{
Relembra "[...] o desenvolvimento do capitalismo com a exploração do proletariado; o surgimento do socialismo; e, por fim, o eclodir das novas morfologias de trabalho, marcadas pela evolução tecnológica e por uma psicopatologia do trabalho característica."

Assim começa outra forma de superexploração do labor humano, uma nova forma de escravidão; o operário passou a estar preso ao trabalho porque dele dependia sua sobrevivência. Mas eram condições de trabalho degradantes, a jornada extenuante retirava dele, praticamente, toda a possibilidade de lazer e de contato com a família. (AZEVEDO NETO, 2015, p. 38).
}

Essa nova forma de escravidão, também denominada de escravidão moderna, “[...] possui sentido metafórico, eis que não se está mais explicando a compra e venda de pessoas e sim relações de trabalho extremamente precárias [...]”, como explicita Marco Antônio César Villatore (2018, p. 26). O autor ressalta que "[...] os trabalhadores são forçados a laborar em jornadas extenuantes para perceber uma remuneração ínfima, quando não adquirem somente dívidas com o seu empregador. São relações extremamente violentas, ainda que tal violência não seja necessariamente física e sim psicológica." (VILLATORE, 2018, p. 26).

Por certo, os modelos de produção instituídos, bem como a ofensiva do capital sobre o trabalho, acarretaram como consequência um mundo do trabalho desregulamentado, com altos índices de desemprego e uma condição de estranhamento na subjetividade dos trabalhadores que por fim reforça a importância do vínculo entre trabalho e dignidade humana.

\section{Pandemia e Trabalho - a estranheza do ócio}

O ano de 2020 se apresentou de forma atípica. Quem poderia imaginar que o mundo precisaria se unir para empreender esforços no sentido de conter o avanço de um vírus. Em 30 de janeiro de 2020, a Organização Mundial da Saúde (OMS), declarou, “[...] que o surto da doença causada pelo novo coronavírus (COVID-19) constitui uma Emergência de Saúde Pública de Importância Internacional - o mais alto nível de alerta da Organização, conforme previsto no Regulamento Sanitário Internacional. "(PAHO, 2020, n.p.). 
Diante do quadro apresentado, em 11 de março de 2020 a COVID-19 foi caracterizada pela OMS como uma pandemia, e desde então, a Organização Pan-Americana da Saúde (OPAS) e a OMS prestam apoio técnico ao Brasil e demais países, na preparação e resposta ao surto de COVID-19 (PAHO, 2020, n.p.).

Em meio a pandemia, além da saúde, o trabalho é o outro lado da questão que assola a sociedade, pois é no mercado de trabalho que se reflete as mudanças socioculturais de momentos críticos como estes causados pela pandemia. $\mathrm{O}$ cenário de incerteza, o medo de perder o emprego, a insegurança devida aos problemas de saúde pública, afeta e desestabiliza por demais o trabalhador, pois a pandemia acabou por servir como um grande laboratório de testes para novas relações de trabalho, novas tecnologias de sistemas mais eficientes e de organização dos negócios. O precariado fica latente.

O trabalhador foi tomado de assalto pela pandemia, e de uma hora para outra se vê no prejuízo em relação às suas poucas horas de ócio. "A quietude e o silêncio estão em perigo. A conectividade preenche cada espaço no tempo." (STANDING, 2017, p. 194). O teletrabalho ${ }^{3}$, imposto como medida de enfrentamento do estado de calamidade pública, afeta sem dúvida alguma a saúde do trabalhador.

Visando as regras do distanciamento social, o trabalho realizado em casa (teletrabalho), foi a medida cabível e necessária. Contudo, houve um significativo crescimento de tarefa, de trabalho por tarefa que, segundo Stading (2017), são responsáveis por consumir o ócio.

A falta de respeito pelo ócio e pela 'indolência' reprodutiva e produtiva é um dos
piores resultados da sociedade de mercado mercadorizada. Quem experimenta tarefa
e trabalho intensos descobre que mente e corpo estão 'exaustos' e têm pouca energia
ou inclinação para fazer qualquer coisa que não seja entregar-se à 'diversão' passiva.
As pessoas que estão exaustas querem relaxar na 'diversão', muitas vezes assistindo
a uma tela ou conduzindo um diálogo com uma série de telas. É claro que todos nós
precisamos nos 'divertir' de alguma maneira. Mas se a tarefa e o trabalho são tão
intensos, pode ser que não tenhamos nenhuma energia ou disposição para participar
em atividades de ócio mais ativas. (STANDING, 2017, p. 195).

A forma de realizar um trabalho, bem como a forma de se relacionar com esse trabalho, mudou. É tênue, a linha imaginária que separa vida pessoal e vida profissional, que por vezes se confundem ou até deixam de existir. A modernidade ou pós-modernidade, não importa, alterou significativamente e definitivamente as Relações de Trabalho. A expectativa criada a

\footnotetext{
3 "Considera-se teletrabalho a prestação de serviços preponderantemente fora das dependências do empregador, com a utilização de tecnologias de informação e de comunicação que, por sua natureza, não se constituam como trabalho externo". (Art. 75-B, da Lei 13.467/2017).
} 
partir da globalização para com o trabalho, foi a abertura de novas condições de produção e consequentemente, de novas frentes de trabalho.

No entanto, a respeito disso criou-se um imaginário social e ocorre que, apesar dessa abertura proporcionada pela globalização, a mesma proporcionou forças adversas que seguem na contramão, provocando tensões e acarretando desigualdade, migrações e desemprego, um verdadeiro abismo social. Flexibilização, terceirização, trabalho remoto, home office são realidades desejadas por alguns, estranhas e rejeitadas por outros. Paradigmas foram quebrados, assim como também o padrão linear de tarefas executados pelas gerações passadas.

O precariado, como camada social do trabalhador, é contraditório e está longe de ser homogêneo. A pandemia consolidou o que já existia.

\begin{abstract}
Além da falta de garantia no emprego e da renda social insegura, aqueles que fazem parte do precariado carecem de uma identidade baseada no trabalho. Quando estão empregados, ocupam empregos desprovidos de carreira e sem tradições de memória social, ou seja, não sentem que pertencem a uma comunidade ocupacional imersa em práticas estáveis, códigos de ética e normas de comportamento, reciprocidade e fraternidade. (STANDING, 2017, p. 31).
\end{abstract}

O mundo contemporâneo do trabalho e seus respectivos trabalhadores, requerem em comum, a autonomia, a liberdade e a mobilidade, possíveis de serem encontrados nas novas modalidades de trabalho. Porém, a via pela qual esses desejos seguem pode acarretar danos à qualidade de vida do trabalhador. O tempo de trabalho e de vida social do trabalhador precisam ser administrados. A fragmentação do trabalho pode levar o trabalhador à exaustão, ao isolamento social, à exploração moderna. O tecido social necessita de interações coletivas. Em sociologia das ausências, Santos (2004, p. 797) traz uma abordagem sensível dos vazios causados por uma razão moderna indolente, originado de um paradigma moderno que chegou à exaustão.

Mesmo entre o limite da necessidade e do sofrimento, "O trabalho é o que permite, é o que organiza o encontro com o outro. Ele constitui uma ocupação. É um meio de lutar contra a monotonia da vida, de encher o vazio, de passar o tempo. " (LINHART, 2007, p. 43). No entanto, é preciso administrar. "Não há nada de errado com a conectividade; é o contexto que importa. ”. (STANDING, 2017, p. 194).

Ribeiro (2014, p. 72) quando cita Spivak (2010), lembra que enquanto houver a pretensão de ser porta-voz do outro, sem se importar efetivamente com o outro, haverá certamente muitos silêncios intraduzíveis e que jamais serão audíveis. O autor reforça a necessidade do engajamento efetivo na subversão das estruturas de subalternização que mantêm populações inteiras emudecidas. 
Característico a tal descrição, tem-se que o trabalho cuja jornada é exaustiva e sobrecarrega as forças físicas e mentais do trabalhador, não é Trabalho Decente, e, o modo silencioso de submetê-lo ao poder do patrão, é uma forma de silenciar o trabalhador que se sujeita à situação por questões de necessidade e sobrevivência. Ficar em casa não é uma opção para quem tem família e conta com pouco ou nenhum direito social. Este é o cenário que se instala freneticamente diante do estado pandêmico enfrentado atualmente.

\section{0 enlace da Fraternidade}

Da conjuntura histórica, depreende-se que a fraternidade já era amplamente praticada antes de 1789, não se limitando, portanto, ao contexto da Revolução Francesa. De natureza complexa, muito ligada a ideia do cristianismo, foi impedida de obter um reconhecimento geral, sendo necessário um longo período de tempo para que seu conceito fosse retomado e encontrasse um novo consenso. "A Revolução de 1848 é o primeiro exemplo de várias tentativas, ocorridas na história dos dois últimos séculos, de se construir uma universalidade em torno de sucessivas reinterpretações [...] do conceito de fraternidade" (BAGGIO, 2008, p. 12).

O resgate e a concretização do princípio da fraternidade são fundamentais para que
seja possível o enfrentamento de todos os problemas sociais ainda presentes na
sociedade pós-moderna, como uma maneira efetiva de respeitar a dignidade de todas
as pessoas humanas enquanto princípio universal que deve ser garantido para todos
os cidadãos que fazem parte da Humanidade (OLIVEIRA, 2013, p. 33).

O princípio esquecido, como Baggio (2008) denomina a fraternidade, foi uma tentativa de romper com o despotismo e a tirania da monarquia absolutista, e pela primeira vez, o lema da Revolução Francesa de 1789 representou a ideia de fraternidade como uma interpretação política. Contudo, a fraternidade se mostra desprovida de poder, e vai além, pois sugere a reciprocidade (horizontal), diferindo-a do princípio da solidariedade.

Ao longo da história, a fraternidade criou uma consciência coletiva pautada na reciprocidade e comprometida com virtudes positivas, que visam o bem e a justiça social, necessárias para nortear a conduta e a convivência dos seres humanos. Andrade (2010, p. 221) acentua pela fraternidade o reconhecimento do Outro, de modo que "[...] eu me reconheço a mim mesmo humano por intermédio do outro que igual a mim merece ser reconhecido por mim, não apenas como consciência de si, mas como consciência para si onde me ponho para fazê-lo reconhecer-se humano". 
Corroborando tal entendimento, para Veronese (2015, p. 102) o princípio da fraternidade " [...] há de ser contemplado levando-se em consideração as esferas aparentemente opostas de Participação e Comprometimento”, ou seja, “[...] o princípio da Fraternidade pode ser semanticamente conceituado como Participação Comprometida" (VERONESE, 2015, p. 102-103). Trata-se de uma condição a ser conquistada coletivamente e voltada para o ideal coletivo, para o comunitário. Nesse ideal coletivo, a fraternidade remete a ideia de um Outro diferente, do qual tenho deveres e responsabilidades, e não somente direitos a opor (TOSI, 2009).

[...] ao enfatizar a liberdade e a igualdade em detrimento da fraternidade, a Modernidade acentuou os aspectos individualistas e egoístas dos Direitos Humanos, esquecendo o caráter social, fraterno e solidário desses mesmos Direitos, que não são simplesmente do indivíduo e dos grupos ou classes, mas também do 'outro', do mais pobre, do mais desfavorável. (TOSI, 2009, p. 59).

É característico da fraternidade desempenhar um papel transformador entre os sujeitos, entre a comunidade, ou seja, com o Outro. A fraternidade “[...] não esgota a sua fecundidade nas relações interpessoais de proximidade, estende-se às relações sociais mais amplas, às relações entre grupos sociais, às relações políticas e internacionais. " (PATTO, 2013, p. 35). A fraternidade viabiliza o enfrentamento das diferenças, seja político, econômico, social, nos âmbitos micro (locais) ou macro (universais).

O reconhecimento do que há de comum no outro, na sua condição humana permite estabelecer um estreitamento nas relações humanas. Permite reconhecer que todos possuem um corpo, que podem sofrer as mesmas dores e sentir os mesmos sentimentos, ou seja, precisamos como acentua Tosi $(2009$, p.63) “[...] do reconhecimento social e afetivo, ser reconhecidos em nossa identidade e diversidade. " São condições essenciais para superar a lógica individualista, de interesse de classes e grupos específicos.

A fraternidade é um compromisso que favorece o desenvolvimento autenticamente
humano do país, sem isolar as categorias mais frágeis, sem excluir ninguém do bem-
estar, sem criar novas formas de pobreza. Defende os direitos de cidadania e facilita
o acesso a eles, abrindo a esperança a todos aqueles que almejam uma vida digna...
(LUBICH, 2000, p. 1).

Pode-se dizer que a fraternidade reconstrói o tecido social e confere novos significados às experiências humanas, pois reforça os laços do diálogo e propicia a consciência de comunhão, de unidade familiar, de socialidade. Ela promove mais encontros, mais convivência e menos fragmentação.

O despertar do homem para sua humanidade é condição de possibilidade que só se constitui quando ele tem a compreensão de si mesmo e do outro, consciente da sua condição íntegra de se (re) construir infinitamente para se tornar capaz de gozar pacificamente de todos os seus deveres, em um desenvolvimento relacional completo para viver e conviver em Sociedade. (SILVA, 2009, p. 86). 
Suas aspirações não se limitam à individualidade. O Outro faz parte da sua condição de existir nessa sociedade, pois a fraternidade consiste na responsabilidade com a vida e o bemestar recíprocos, conferindo constante preocupação e respeito à dignidade da pessoa humana. Aquini (2008, p. 137), aduz que a fraternidade está “[...] na origem de um comportamento, de uma relação que deve ser instaurada com os outros seres humanos, agindo uns em relação aos outros, o que implica também a dimensão de reciprocidade. "

Percebe-se, portanto, que a fraternidade é geradora de relações de outridade, que orienta para um porvir pautado na igualdade social e cultural, na diversidade, na consideração e reconhecimento pelo outro.

\section{Considerações finais}

As alterações vivenciadas no mundo do trabalho têm servido de constante reflexão. A pandemia acelerou o processo de digitalização já existente no mundo corporativo e quebrou resistências, como o home-office por exemplo. A conectividade foi o meio de estreitar as relações sociais, num momento cuja exigência é exatamente o oposto: o distanciamento social.

É inexorável, em que pese toda sua acepção histórica e social, que o trabalho influencia na vida de cada ser humano e nos mais variados aspectos. Embora seja fundamental, pois a partir dele é possível obter frutos ou alcançar bens que satisfaçam as necessidades básicas e vitais, o mesmo se reveste com nuança e conotações de servidão pelas condições degradantes de trabalho.

Lamentavelmente, o mundo contemporâneo não somente avançou nos aparatos de tecnologia e automação, mas também progrediu significativamente nas variadas formas de precarização do trabalho. A flexibilização, a terceirização e a pejotização são algumas das formas que visam precarizar o mercado de trabalho e destruir os direitos sociais arduamente conquistados pela classe trabalhadora.

Não obstante à toda questão jurídica que já permeava e preocupava a vida do trabalhador, a crise instalada pela pandemia impactou de forma significativa, pois a mesma permite diversas interpretações, arbitrárias ou pouco razoáveis, visto que não há previsão legal para um fenômeno tão excepcional.

O home-office ou teletrabalho, alternativa encontrada para dar continuidade às atividades de trabalho nesse período de pandemia, alterou o funcionamento da sociedade e da produção que era baseado em blocos de tempo e de locais de trabalho, ou seja, mudou a rotina, fracionou o tempo de ócio. Durante o período da quarentena, tais modalidades de trabalho 
aliadas às regras do isolamento social para a COVID-19, revelaram questões outras que assolam os trabalhadores, identificadas como exaustão, ansiedade e stress.

Diante desse contexto formulou-se a problemática do presente artigo: "Como é possível amenizar as questões transversais que assolam o trabalhador no período da pandemia?"

A hipótese articulada para a problemática apresentada se pauta na Fraternidade como possível caminho para restabelecer a identidade do trabalhador, pois ela desempenha um papel de transformação social.

A conectividade constante e acelerada tomou conta do cotidiano. Feriados e finais de semana diluíram-se na quarentena. Perdeu-se a noção do tempo. O local de trabalho está em todo lugar e a restrição do tempo transforma o ócio, pois preencher o tempo passou a ser um desafio. As pessoas encontram-se vulneráveis às distrações e vícios que um mundo conectado oferece e isso pode ser um risco ao senso de territorialidade humana, pois o ser humano precisa interagir.

Nesse sentido, a fraternidade é o enlace que permite uma interação universal. Ela une preocupações individuais e pretensões universais ao promover a reflexão e o movimento ético para a consecução de relações pautadas na empatia, na compreensão, no reconhecimento, e no sentimento de pertença. Pela fraternidade, é possível superar o medo do contágio, abandonar o espírito de competição, desacelerar o ritmo acelerado de trabalho, recuperar o tempo do ócio e lhe atribuir qualidade de vida.

Resgatar o princípio da fraternidade, sobretudo em momentos críticos que afrontam a vida do ser humano, como nesse vivido na pandemia da COVID-19, é fundamental, pois se trata de um princípio que resgata a comunhão de pactos entre os sujeitos diferentes e considera suas histórias e vivências, e não apenas sua renda e posição social. A fraternidade consiste na ajuda recíproca, e isso se estende às relações sociais mais amplas.

Não é possível superar uma pandemia individualmente. Faz-se necessário uma sutura entre o mundo pessoal e o mundo público que estabiliza os sujeitos aos mundos culturalmente habitados, tornando-os reciprocamente unificados, emergindo assim o processo de identificação.

A convivência com as diferenças exige o enfrentamento de problemas sociais, seja do mesmo nível institucional ou não. Isso pressupõe a necessidade de um instrumento (fraternidade) que viabilize a superação de tal obstáculo. A fragilidade da sociedade diante de tal cenário corresponde ao tamanho da crise do trabalho. E, sob esse aspecto a fraternidade é bem-vinda. 


\section{REFERÊNCIAS}

ANDRADE, Maria Inês Chaves de. A fraternidade como direito fundamental entre o ser e o dever ser na dialética dos opostos de Hegel. Coimbra: Almedina, 2010.

ARENDT, Hannah. A condição humana. Tradução de Roberto Raposo. Posfácio de Celso Lafer. 10. ed. Rio de Janeiro: Forense Universitária, 2007.

AQUINI, Marco. Fraternidade e direitos humanos. In: BAGGIO, Antonio Maria. (Org.). O Princípio Esquecido/1. Vargem Grande Paulista, SP: Cidade Nova, 2008.

AZEVEDO NETO, Platon Teixeira de. O trabalho decente como um direito humano. São Paulo: LTr, 2015.

BAGGIO, Antônio Maria. A ideia de fraternidade em duas Revoluções: Paris 1789 e Haiti 1791. In: BAGGIO, Antônio Maria (Org.). O princípio esquecido/1. Vargem Grande Paulista, SP: Cidade Nova, 2008.

BATTAGLIA, Felice. Filosofia do trabalho. São Paulo: Saraiva, 1958.

DEJOURS, Christophe. Conferências brasileiras: identidade, reconhecimento e transgressão no trabalho. Tradução: Ana Carla Fonseca Reis. Revisão técnica: Maria Irene Stocco Betiol e Maria José Tonelli. São Paulo: Fundap: EAESP/FGV, 1999.

FERRARI, Irany; NASCIMENTO, Amauri Mascaro; MARTINS FILHO, Ives Gandra da Silva. História do trabalho, do direito do trabalho e da justiça do trabalho: homenagem a Armando Casimiro Costa. 2. Ed. São Paulo: LTr, 2002.

GAULEJAC, Vicent de. Gestão como doença social: ideologia, poder gerencialista e fragmentação social. Tradução: Ivo Storniolo. Aparecida, SP: Ideias \& Letras, 2007. (Coleção Management, 4).

LINHART, Danièle. A desmedida do capital. Tradução: Wanda Caldeira Brant. São Paulo: Boitempo, 2007. (Mundo do trabalho).

OLIVEIRA, Olga Maria Bosch Aguiar de. O movimento da inconfidência mineira de 1789: a busca pela liberdade sem fraternidade. In: Direito e fraternidade. Josiane Rose Petry Veronese e Olga Maria Bosch Aguiar de Oliveira (Orgs.). Rio de Janeiro: Lumen Juris, 2013, p. 1-36.

DUDH. Declaração universal dos direitos humanos. Nações Unidas do Brasil (ONU). Artigo 1: Todos os seres humanos nascem livres e iguais. Publicado em 13/11/2018. Disponível em: https://nacoesunidas.org/artigo-1-todos-os-seres-humanos-nascem-livres-eiguais/. Acesso em: 06 jun. 2020.

LUBICH, Chiara. A fraternidade universal. Trechos do discurso proferido a parlamentares italianos, Palazzo San Macuto, Roma, 15.12.2.000. In: Movimento político pela unidade. Movimento dos focolares. Disponível em: http://www.mppu.org.br/novo/download/pdf/A_Fraternidade_Universal_-

_Chiara_Lubich.pdf. Acesso em: 12.jun. 2020. 
PAHO. Organização Pan-Americana da Saúde. Organização Mundial da Saúde, OPAS/Brasil. Folha informativa - COVID-19 (doença causada pelo novo coronavírus). Atualizada em 29 de maio de 2020. Disponível em:

https://www.paho.org/bra/index.php?option $=$ com_content\&view $=$ article\&id $=6101$ :covid19\&I temid=875. Acesso em: 30.05.2020.

POLANYI, Karl. A grande transformação: as origens de nossa época. Tradução de Fanny Wrobel. 2. ed. Rio de Janeiro: Campus, 2000.

PRONI, Marcelo Weishaupt. Duas teses sobre o trabalho no capitalismo. Cienc. Culto. São Paulo, v. 58, n. 4, p. 23-25, dezembro de 2006. Disponível em:

http://cienciaecultura.bvs.br/scielo.php?script=sci_arttext\&pid=S0009-

67252006000400013\&lng=en\&nrm=iso. Acesso em: 1 jun. 2020.

RIBEIRO, Adelia Miglievich. Por uma razão decolonial - Desafios ético-políticoepistemológicos à cosmovisão moderna. In: Dossiê: Diálogos do Sul. Civitas: Porto Alegre v. 14 n. 1 p. 66-80 jan.-abr. 2014.

SANTOS, Boaventura de Sousa. Para uma sociologia das ausências e uma sociologia das emergências. In: Boaventura de Sousa Santos (Org.). Conhecimento prudente para uma vida decente: 'um discurso sobre as ciências' revisitado. São Paulo: Cortez, 2004. p. 777821.

SILVA, Ildete Regina Vale da. A fraternidade como um valor que o direito pode e deve (re)construir: uma abordagem à luz dos direitos humanos e dos direitos fundamentais. Orientador: Paulo de Tarso Brandão. Dissertação (mestrado). Programa de Mestrado em Ciência Jurídica da Universidade do Vale do Itajaí - UNIVALI, Itajaí/SC, 2009.

SOUTO MAIOR, Jorge Luiz. Curso de direito do trabalho: teoria geral do direito do trabalho. vol. 1, parte 1. São Paulo: LTr, 2011.

STANDING, Guy. O precariado: a nova classe perigosa. Tradução Cristina Antunes. Belo Horizonte: Autêntica Editora, 2017.

TOSI, Giuseppe. A fraternidade é uma categoria política? In: BAGGIO, Antonio Maria (Org.). O Princípio Esquecido: exigências, recursos e definições da fraternidade política. Vargem Grande Paulista/SP: Cidade Nova, 2009, Vol. 2.

VERONESE, Eduardo Rafael Petry. Um conceito de fraternidade para o direito. Rio de Janeiro: Lumen Juris, 2015.

VILLATORE, Marco Antônio César; CHARÃO, Anderson Pereira. A mão de obra migrante como traço da escravidão moderna. In: CAVALCANTE, Jouberto de Quadros Pessoa; VILLATORE, Marco Antônio César; AFONSO, Túlio Augusto Tayano (Coords.). Direito internacional do trabalho e a organização internacional do trabalho: trabalho dos imigrantes, refugiados e trabalho fronteiriço. São Paulo: LTr Editora, 2018.

WANDELLI, Leonardo Vieira. O direito fundamental ao conteúdo do próprio trabalho: uma reconstrução normativa do direito ao trabalho. In: Revista Espaço Jurídico: Espaço Jurídico 
Journal of Law [EJJL]/Universidade do Oeste de Santa Catarina. v. 17, n. 3, p. 1013-1036, set./dez. 2016. Joaçaba: Editora Unoesc, 2016.

ZANGRANDO, Carlos Henrique da Silva. Curso de direito do trabalho. São Paulo: LTr, 2008. 